\title{
Narrativas híbridas: 0 estático e o móvel no vídeo "911" do coletivo cia de Foto
}

\author{
RAFAEL CASTANHEIRA
}

\section{Resumo}

Este artigo propõe-se a analisar o vídeo "911", produzido pelo coletivo de fotógrafos Cia de Foto, a fim de refletir sobre as suas características técnicas e estéticas que apontam para novas formas de edição e apresentação dos temas no documentário fotográfico contemporâneo. Ao mesclar fotografias estáticas e imagens em movimento, o coletivo desafia o modelo tradicional da narrativa realista do fotojornalismo e do documentarismo clássico empregado ao

Palavras-chave: Fotodocumentário, narrativas híbridas, Cia de Foto longo de todo o século XX, assumindo abertamente a ficção como possibilidade para a construção de novas visualidades e representações sobre as questões sociais no mundo hoje. 


\section{Hybrid narratives: the static and the mobile in the " 911 " Cia de Foto video}

\section{RAFAEL CASTANHEIRA}

\begin{abstract}
This article aims to analyse the video "911" produced by the collective of photographers Cia de Foto to reflect about its technical and aesthetical characteristics that point to new forms of editing and presenting the subjects in contemporary documentary photography. When combining static and moving images, the collective challenges the traditional model of the realistic narratives made by photojournalism and classic documentary throughout the $20^{\text {th }}$ century. In "911", the fiction is assumed by Cia de Foto as a way of constructing news visualities and representations of the social issues in the world today.
\end{abstract}

Keywords:

Documentary photography, hybrid narratives, Cia de Foto 


\section{Narraciones híbridas: lo estático y el movimiento en el video 911 del colectivo cia de Foto}

\section{RAFAEL CASTANHEIRA}

\section{Resumen}

Este artículo tiene el objetivo de analizar el video “911", producido por el colectivo de fotógrafos Cia de Foto, con la intensión de reflexionar a respecto de sus características técnicas y estéticas, apuntando en dirección a nuevas formas de edición y presentación de los temas en el documental fotográfico contemporáneo. Al mezclar fotografías estáticas e imágenes en movimiento, el colectivo desafía el modelo tradicional de la narrativa realista del fotoperiodismo y del documental clásico usado a lo largo de todo el siglo XX,

Palabras-clave: Fotodocumental, narraciones híbridas, Cia de Foto asumiendo abiertamente la ficción para la construcción de nuevas visualidades y representaciones sobre las cuestiones sociales en el mundo actual. 
No os últimos anos, com a evolução tecnológica, ampliaram-se não somente as possibilidades de produção de fotografias pelo uso das câmeras digitais, como também as suas condições de circulação pela internet. Se, por um lado, o advento da fotografia digital tornou ainda mais tênue a fronteira entre realidade e ficção no campo fotográfico devido a sua facilidade de manipulação, por outro, estes novos recursos técnicos contribuíram de maneira significativa para o aumento da produção de imagens, que passam a registrar e difundir realidades com uma profusão nunca antes vista - incluindo a produção de vídeos que promovem um diálogo entre a fotografia estática e as imagens em movimento, ponto central a ser abordado nesse artigo.

Hoje, as câmeras fotográficas digitais também filmam em alta resolução e, por isso, passam a ser amplamente utilizadas por fotógrafos que buscam mesclar cenas estáticas com cenas em movimentos a fim de produzir bens audiovisuais com diferentes linguagens - escrita, musical, fotográfica e videográfica. Trata-se, dessa forma, de deslocar funções particulares de cada linguagem com intuito de criar narrativas híbridas, o que caracteriza de maneira significativa a produção imagética do começo do século XXI e coloca em discussão os limites de uso e o espaço da fotografia no mundo atual.

A produção de vídeos com fotografia estática tem se tornado uma prática comum entre fotógrafos que enxergam nessa fusão novas possibilidades de criação e apresentação de suas narrativas. E, mais especificamente no terreno da reportagem e de conteúdos de caráter documental, o que se vê atualmente é a presença da fotografia estática na tela do audiovisual se misturando a imagens em movimento para criar formas expressivas que toquem a sensibilidade do espectador contemporâneo 
- aquele mais conectado aos meios virtuais como sites, blogs e redes sociais disponíveis nas plataformas multimidiáticas da internet, do que aos meios noticiosos impressos.

Ao contrário das narrativas jornalísticas tradicionais que apresentam, em meio aos textos, uma ou mais imagens impressas nas páginas de jornais ou nas revistas ilustradas, as narrativas híbridas potencializam a capacidade discursiva do narrador ao conjugar diferentes suportes de comunicação e demanda ao seus receptores - antes acostumados com o modelo hegemônico das narrativas lineares entendidas como pura representação da realidade - leituras interpretativas de seus conteúdos como, por exemplo, o vídeo "911" produzido pelo coletivo Cia de Foto, a ser analisado no presente trabalho.

Neste sentido, pode-se refletir, de maneira mais específica, sobre a construção das narrativas atuais no campo da produção audiovisual de cunho documental. Quais são os possíveis impactos provocados pelas novas tecnologias nos conceitos tradicionais de fotografia como documento e como se dá a relação do documentário fotográfico com o vídeo de curta duração em uma época marcada pela liberdade de procedimentos e hibridismos destas linguagens?

\section{As novas tecnologias e a fotografia como documento}

Em seu livro A fotografia: entre documento e arte contemporânea (2009), o teórico francês André Rouillé afirma que a fotografia surge na metade do século XIX para reformar o "regime de verdade" de uma época na qual as imagens manuais (pintura, desenho, gravura) tinham a função de representar a realidade. Para a sociedade daquele período, a fotografia tornava-se necessária, pois trazia uma visão credível, uma verdade irrefutável, gerando a confiança indispensável à ciência. Dessa forma, a fotografia vai exercer um papel capital de mediação entre os homens e o mundo, pois suas características, como a reprodutibilidade, a fácil mobilidade, a rapidez de produção e a credibilidade do seu conteúdo, vão mantê-la em "sintonia com o sistema, os valores e os mais emblemáticos fenômenos da sociedade industrial: a máquina, as grandes cidades e esta extraordinária rede que as interliga, a estrada de ferro" (ROUILLÉ, 2009, p. 48).

O valor documental da fotografia baseia-se em seu dispositivo técnico (ótico e químico), mas isso não é suficiente para garanti-lo, já que esse valor é oriundo de um caráter histórico - portanto, momentâneo - estabelecido pela sociedade in- 
dustrial e "varia em função das condições de recepção da imagem e das crenças que existem a respeito" (ROUILLÉ, 2009, p. 28). Em razão do advento da sociedade pós-industrial, ou sociedade da informação, na qual o sistema de comunicação é dominado pela televisão, pelos satélites e, depois pelas redes digitais, as "imagens-documento" são substituídas por imagens tecnológicas, muito mais rápidas e sofisticadas (ROUILLÉ, 2009, p. 65).

O fotodocumentário do modelo paradigmático do começo século $\mathrm{XX}$, ou seja, aquele que usa a fotografia enquanto imagem "objetiva" e "unívoca", encontra-se em crise, em pleno declínio histórico de seus usos práticos já que:

O documento fotográfico tornou-se incapaz de responder às necessidades dos setores cultural e tecnologicamente mais avançados - principalmente a pesquisa e a produção dos produtos, dos conhecimentos e dos serviços -, porque o real da sociedade pós-industrial não é mais o mesmo real da sociedade industrial; porque em medicina, por exemplo, a fotografia e a radiografia não permitem acesso ao mesmo real do corpo que as ecografias, os dopplers, os escâneres, e sobretudo as imagens por ressonância magnética nuclear (IRM); porque a fotografia impressa não é capaz de rivalizar com a informação televisiva difundida continuamente e ao vivo por satélite. $\mathrm{O}$ novo real convoca novas imagens, novos dispositivos de imagens para novos modos de crença (ROUILLÉ, 2009, p. 65).

Segundo Rouillé (2009), esse "novo real" impõe, consequentemente, novas formas de produção de imagens para "novos modos de crença", haja vista que a partir dos anos 1970 as fotografias começam a suscitar desconfianças por parte da sociedade devido ao controle de sua produção e divulgação: a forma de editar e expor as imagens, a produção de legendas que mudam o sentido da cena e, finalmente, a manipulação digital.

No que diz respeito às discussões acerca da relação da fotografia com o real, a questão da manipulação sempre vem à tona (BEAUMONT, 1997). Desde a sua invenção, a crença na capacidade da fotografia de registrar o real foi desmistificada por artistas que, ao produzir suas imagens, envolviam uma carga de ficcionalidade por meio da construção de cenas, poses e luminosidade previamente pensadas e da colagem de negativos de situações diversas que, justapostos numa mesma imagem, fraturavam, assim, a ideia de realidade na fotografia (BEAUMONT, 1997). 
Entretanto, no contexto atual da fotografia digital, a manipulação se tornou prática comum e quase indissociável de sua produção. Para Machado (1997, p. 243), diferente da manipulação "grosseira" do passado que "podia ser facilmente descoberta”, hoje a manipulação pode ser feita através do processamento digital que adiciona ou suprime qualquer elemento na fotografia sem deixar nenhuma marca de alteração. Assim, "a conclusão lógica é que, no limite, todas as fotografias são suspeitas e que, também no limite, nenhuma foto pode ser legal ou jornalisticamente provar coisa alguma" (MACHADO, 1997, p. 243).

É preciso dizer que Machado publicou seu livro Pré-cinema e pós-cinema em 1997, sendo no Brasil um dos pesquisadores pioneiros nos estudos sobre a hegemonia da eletrônica no campo midiático. À época, Machado já afirmava que, ao perder seu poder de produzir verossimilhança, a fotografia poderia, dentro de mais algum tempo, ser excluída de nossos documentos de identidade. Tal fato ainda não aconteceu, mas ao dizer que "no tempo da manipulação digital das imagens, a fotografia já não difere da pintura, já não está isenta de subjetividade e já não pode atestar a existência de coisa alguma" (1997, p. 242), toca numa importante questão sobre o fato de, na contemporaneidade, o registro fotográfico ser explorado mais pela suas capacidades gráficas do que pelas fotográficas, ou seja, a fotografia, assim como a pintura, seria explorada mais por suas qualidades pictóricas do que por aquelas documentais que supostamente a tornaria fiel ao mundo visível.

Machado (1997) chama de "pixelização" este movimento de informatização dos sistemas de expressão e comunicação do homem contemporâneo que se dá não apenas na fotografia, mas em todas as esferas da cultura, e que seria responsável pela mudança dos hábitos perceptivos do público em relação às novas características da imagem na era eletrônica ou, segundo Rouillé (2009), na "era pós-industrial", a era da informação. Assim, a imagem digital funcionaria como "texto", texto visual, e para ser lida precisaria ter seus códigos decifrados por seus espectadores - ao contrário da fotografia, entendida pelo público leigo por pelo menos 150 anos, como representação fiel da realidade a ser contemplada (MACHADO, 1997). Dito de outra maneira, as imagens contemporâneas, mesmo manipuladas, podem tratar da realidade, mas de uma realidade mediada e que agora passa a ser acessada por espectadores cada vez mais familiarizados com os processos criativos de seus produtores e, portanto, menos ingênuos acerca dos seus processos de construção de sentidos. 
Nesse novo regime de visualidade, supostamente transformado pelas tecnologias digitais, a fotografia (e o cinema) teria tomado uma trajetória, como sugere Sutton (2009, p. 2, tradução nossa), que culminou numa "estética unificadora daquilo que muitos chamam de convergência". Mas, no entanto, prossegue Sutton (2009, p. 2, tradução nossa),

[...] na convergência, às vezes, a tecnologia altera a prática e provoca um impacto como quando do advento da telefonia móvel e da Internet as quais afetaram dramaticamente onde, como e com quem nos comunicamos. Noutros tempos era a prática que subordinava a nova tecnologia e isso é o que, devido aos protestos acadêmicos pelo contrário, tem acontecido com a fotografia e o cinema. ${ }^{1}$

Ao citar Vidocq (PITOF, 2001) como o primeiro filme produzido inteiramente com tecnologia digital e que, nem por isso, apresentou uma estética inovadora - ao contrário, Vido$c q$ mostra uma Paris de 1930 com uma estética similar àquela dos filmes em $35 \mathrm{~mm}$-, Sutton (2009) argumenta que a tecnologia digital não seria tão importante nos dispositivos artísticos quanto se pensou quando do seu advento, pois não teria sido um fator determinante para as mudanças estéticas na fotografia e no cinema.

Em seu livro Photography, cinema, memory: the crystal image of time (2009), Sutton afirma que a "chegada das tecnologias digitais não foi apenas uma intervenção tecnológica que muda a vida das pessoas, mas também as trouxe de volta ao estado natural das relações em que a poética, representada pela pintura, é o regime predominante" (p. 3, tradução nossa). ${ }^{2}$ Esta ideia corrobora com a de Machado (1997) que compara a fotografia digital com a pintura, pois ambas estariam marcadas pela capacidade de metamorfose ao permitirem transformações de diversas ordens em suas superfícies. Sutton (2009, p. 3), no entanto, é menos otimista com a propagada "revolução" que as tecnologias digitais teriam causado no mundo das imagens, pois acredita que elas não provocariam mudanças em nível social. Mas poderiam apenas prover possibilidades potenciais ou precárias de mudança, já que a mudança tecnológica não é tão significante como a mudança de ideias que a acompanha.

Por outro lado, sugere Sutton (2009, p. 4, tradução nossa), as tecnologias digitais nos trazem de volta ao regime poético - antes representado pela pintura - e "este efeito do evento 
tecnológico sugere que a interface, ou a luta, entre o velho e o novo aconteça não apenas na imagem, mas também no tempo". Essa convergência, ao permitir que formatos análogos sejam tratados numa mesma informação, sugere que seja o regime poético, e não o tecnológico, que organiza a concepção popular de tempo e memória.

Assim, as tecnologias digitais não seriam um fator determinante na mudança da estética das imagens, pois a mudança das ideias seria mais importante do que a tecnologia para alterar as produções fotográficas e cinematográficas do mundo contemporâneo.

\section{Narrativas documentais híbridas e o tempo da fotografia no vídeo}

O manejo do tempo é uma questão crítica na produção de narrativas, pois, como explica Motta (2013), é por meio da "sucessão de estados", ou seja, do desenrolar das ações, que seus sentidos são extraídos pelos seus receptores.

Narrar é relatar eventos de interesse humano enunciados em um suceder temporal encaminhado a um desfecho. Implica, portanto, em narratividade, uma sucessão de estados em transformação responsável pelo sentido. A palavra-chave é sucessão. Ela introduz a questão da sequenciação, ou o desenvolvimento temporal. [...] Narrar é, portanto, relatar processos de mudança, processos de alteração e sucessão interrelacionados. Pressupõe a existência de uma lógica narrativa própria, que nos demanda uma gramática universal (MOTTA, 2013, p. 71).

Os processos de mudança em uma narrativa ocorrem naturalmente em perspectiva com o objetivo de que os acontecimentos se relacionem no tempo, criando passado, presente e futuro. No entanto, o desenvolvimento temporal numa narrativa não precisa necessariamente respeitar essa ordem linear dos acontecimentos assim como ocorre em nossas vidas, pois aquele que narra está descrevendo-os a partir de critérios subjetivos estabelecidos pela sua cultura, pelo seu modo de ver o mundo. Ou seja, narrar implica se colocar na história e, a partir de suas origens e de suas referências culturais, recriar os acontecimentos (MOTTA, 2013, p. 71).

Se narrar implica necessariamente em reconstruir um acontecimento testemunhado (ou imaginado no caso da ficção) a partir dos valores pessoais do narrador, como encarar a narra- 
tiva jornalística diante de conceitos como verdade, credibilidade, objetividade e imparcialidade? Para Motta (2013, p. 82), "as narrativas não são apenas, nem principalmente, puras representações da realidade, mas formas de organizar nossas ações em funções de estratégias culturais em contexto". É ressaltado ainda que todas as narrativas, fictícias ou fáticas, são "construções de sentidos sobre o mundo real ou imaginado". Afinal:

[...] Se a narrativa relata uma estória inventada por alguém, um conto, um romance, uma telenovela, uma história em quadrinhos, por exemplo, é uma ficção, uma construção sobre um universo imaginado que não existe (embora verossímil). Se a narrativa relata uma história verdadeira acontecida no mundo real, uma reportagem sobre uma ocorrência em nossa cidade, a biografia de um político, a descrição de um episódio histórico, por exemplo, é igualmente uma construção discursiva sobre o mundo, uma versão em tantas outras possíveis sobre os episódios ou as pessoas reais (MOTTA, 2013, p. 83).

A fotografia no jornalismo vem enfrentando nas últimas décadas uma grave crise de credibilidade, pois têm buscado, na maioria dos casos, apresentar verdades absolutas em reportagens que exploram temas como a violência, a miséria, o exotismo. Esquecendo-se, por vezes, da vida do cidadão comum, do banal, do cotidiano, do ordinário. Buscando produzir narrativas visuais em linguagem "direta" e balizando-se ainda em conceitos atualmente muitos questionáveis no contexto da pós-modernidade, como imparcialidade e objetividade. Este tipo de projeto documental, que visa à representação do real, tem sucumbido às novas necessidades dos fotodocumentaristas de pensar as diversas possibilidades de apresentação (e construção) das realidades do mundo contemporâneo.

Com o surgimento das novas tecnologias digitais ampliaram-se os processos de produção, circulação e comercialização de fotografias, permitindo que alguns fotodocumentaristas saíssem das redações de jornais para buscar sua autonomia através da edição e veiculação independente de seus trabalhos em sites pessoais, blogs, redes sociais etc. Direcionando-os, muitas vezes, para um campo (e mercado) que tem acolhido a fotografia: o campo da arte contemporânea, no qual podem se pautar livremente a partir de temas que mais lhe interessam e, principalmente, adotar abordagens subjetivas, desenvolvendo seus trabalhos de maneira criativa e sem restrições ou imposições editoriais muito comuns nas redações. 
Questionando os dogmas do fotojornalismo e seu tradicional conceito de "foto-verdade", os projetos documentais contemporâneos buscam registrar temas corriqueiros com enfoques muito pessoais, resultando em imagens enigmáticas e de significações instáveis que, ao invés de impor verdades sobre tais temas, convidam o espectador a refletir sobre as questões abordadas. Como, por exemplo, o vídeo “911", do coletivo Cia de foto que, ao misturar cenas estáticas com movimento, propõe novas formas de leitura da realidade de vida de moradores que ocuparam um prédio abandonado na região central de São Paulo.

\section{O coletivo Cia de foto e o vídeo “911"}

Uma tendência nos últimos anos são os coletivos fotográficos. Reformulando o conceito de cooperativa de fotógrafos, tais como as agências Magnum na França e a $F_{4}$ no Brasil, o coletivo fotográfico é ainda um termo de difícil definição já que representa muito mais do que um grupo de indivíduos que fotografa e se reúne para discutir os próprios trabalhos.

Nos coletivos, a autoria individual do fotógrafo, muito valorizada pelo mercado de arte, é desprezada pelos seus integrantes, que, independentemente do nome inserido como crédito na fotografia, estão produzindo importantes trabalhos no cenário da fotografia contemporânea brasileira, como os fotógrafos do coletivo Cia de foto que "desenvolve trabalhos em várias direções, aproximando linguagens e, assim, questionando o espaço das imagens e seu entendimento". ${ }^{3}$

Criado pelos fotojornalistas do jornal Valor Econômico, Rafael Jacinto e Pio Figueiroa, o coletivo foi fundado em 2003, mas anunciou sua separação em 2013. Durante 10 anos trabalhando com produções autorais ou sob encomenda, em vídeo e fotografia, a Cia de Foto contava ainda com mais dois fotógrafos, Carol Lopes e João Kehl; e a assistente administrativa Flávia Padrão. Juntos, eles dispensavam a autoria de suas fotos e quebraram padrões no meio fotográfico, publicando seus trabalhos como bem entendiam em seu principal meio de divulgação: a internet.

Distribuídos em quatro links (publicidade, retrato, ensaio/art. e blog) o site da Cia de foto, atualmente indisponível, apresentava os mais diversos trabalhos, desde fotorreportagens que abordavam temas políticos e sociais e cenas do cotidiano da cidade de São Paulo, até ensaios publicitários para empresas, intuições e veículos jornalísticos do Brasil. Ainda que realizadas pelos diferentes integrantes do coletivo, suas 
fotografias possuem características similares como, por exemplo, cores fortes, alto contraste, composições e enquadramentos inusitados, personagens meigos em cenários idílicos e personagens grotescos em meio ao caos da maior metrópole brasileira. Trata-se de uma maneira única de documentar na qual - tanto num ensaio autoral quanto num serviço encomendado, ou seja, um trabalho comercial - as linguagens se confundem e, mais uma vez, a personalidade do grupo se sobressai, seja pelo olhar dos fotógrafos, seja pela criatividade no tratamento final das imagens.

Além das séries fotográficas, a Cia de foto produziu narrativas documentais que misturam cenas em movimento, áudio, textos e, principalmente, fotografias. Num momento em que a "sociedade da informação" está cada vez mais baseada na convergência de mídias para acesso a conteúdos informativos - sejam factíveis ou ficcionais - o coletivo Cia de foto aproveitou as potencialidades das novas tecnologias digitais para produzir narrativas não lineares de caráter documental como, por exemplo, o vídeo "911".

"911" documenta a ocupação de um prédio de 29 andares que ficou abandonado por 12 anos. Localizado em uma área de alto valor comercial no centro da capital paulista, mais precisamente no número 911 da Avenida Prestes Maia, o prédio tinha suas fachadas usadas como suporte para propaganda publicitária e durante quatro anos serviu de abrigo para 468 famílias: eram 1.68o latino-americanos e brasileiros das regiões Sul, Norte e Nordeste do país que formavam a maior ocupação vertical urbana da América Latina.

Produzido em 2006 por Alex Carvalho (Twinstudio), o vídeo, com duração de 4 minutos e 57 segundos, apresenta em sequência cerca de 20 fotografias estáticas e cenas em movimento do coletivo Cia de foto. Inicialmente, uma imagem aérea noturna em movimento mostra a parte externa do prédio em meio ao frenesi urbano da região central São Paulo. $\mathrm{Na}$ fachada externa observa-se um grande painel expondo o retrato de uma das moradoras do prédio e que pode ser visto de longe por pedestres e condutores de automóveis que por ali passam entre ruas, avenidas e viadutos. Após a apresentação de um texto de introdução em inglês, o mesmo retrato da moradora (Fig. 1), usado no painel preso à fachada externa do prédio, abre a projeção das imagens sob uma melancólica trilha sonora. Cenas estáticas da arquitetura interna do prédio mostram as más condições de conservação do local: paredes quebradas e sem reboco; corredores e banheiros sujos; rede 


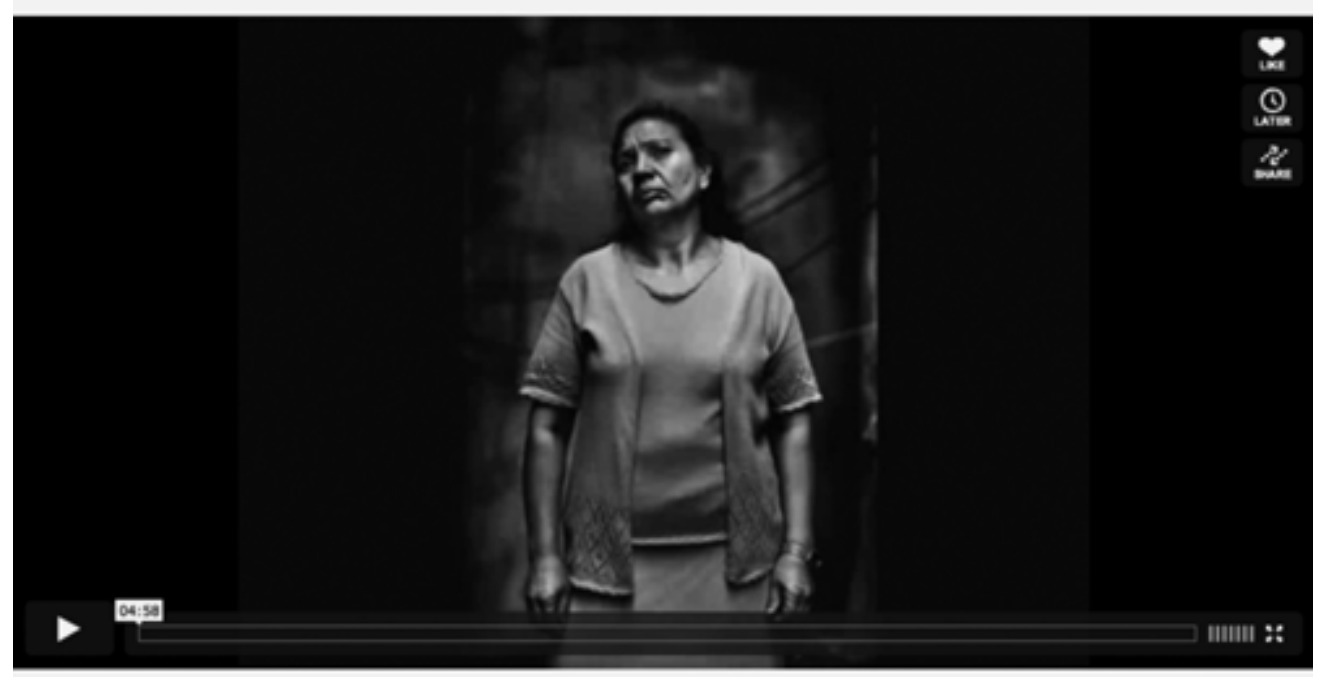

Gif cia de foto : 911

FOTO

from cladeloto nus 3 yeurs ago sor wer wano

Figura 1

“911", Cia de foto, 2006. Vídeo disponível em: $<$ http:// vimeo.com/5820275 $\geq$. Acesso em: o1 abr. 2016. hidráulica e elétrica precárias, expostas pelo teto sem forro; e divisórias de apartamentos feitas de improviso com pranchas de madeira reaproveitadas.

Em meio a essa atmosfera de caos e não pertencimento, uma série de retratos apresenta os moradores em poses que os dignificam. Não são flagrantes de cenas fortuitas. Trata-se de fotografias feitas com consentimento dos fotografados que estão conscientes da presença do fotógrafo e, em sua maioria, olham direto para a câmera. São mães e pais com filhos no colo, crianças, jovens negros e pardos; todos numa relação de dialogismo fotógrafo/fotografado, haja vista que estes são registrados em seus afazeres cotidianos (mulher estende roupa no varal, homem carrega tapete, crianças brincam no pátio) e, em alguns casos, estão em seus ambientes privados (mulher na janela, homem assiste televisão em seu quarto, criança brinca na sala).

Se não fosse a mistura de cenas estáticas com movimento, "911" tratar-se-ia de mais uma projeção de fotografias com trilha sonora. Mas, em sua narrativa, o hibridismo da linguagem fotográfica e videográfica chamam a atenção do espectador por meio do cruzamento da fotografia estática de uma mulher que estende sua roupa no varal com a filmagem de uma segunda mulher que caminha pelo pátio do prédio. Tudo se passa numa mesma cena dividida ao meio por duas personagens 
distintas: a primeira está "congelada" no instante fotográfico e a segunda movimenta-se com o avanço dos frames do vídeo. Dessa maneira, numa mesma cena mesclam-se foto e vídeo, confundindo o espectador que, diante do inusitado, abre-se para as novas possibilidades de abordagem da realidade sem se preocupar com a manipulação digital das imagens e suas possíveis interferências nas narrativas híbridas do mundo contemporâneo dominado pelas tecnologias eletrônicas.

Com o vídeo "911", o coletivo Cia de foto participou da exposição coletiva Geração oo - A Nova Fotografia Brasileira, inaugurada no dia 16 de abril de 2011 no Sesc Belenzinho, em São Paulo, exibindo 170 trabalhos de 52 artistas divididos em dois módulos - "Limites, Metalinguagem" e "Documental Imaginário, Novo Fotojornalismo". Utilizando-se dos zeros dos anos em que os trabalhos foram produzidos, 2001 a 2010 (o1-10), o nome da mostra, Geração oo, faz uma clara referência ao sistema binário, base de toda eletrônica dos computadores e da formação dos pixels das imagens digitais que provocaram um profundo impacto na produção, na circulação e na forma de se pensar a fotografia hoje.

Ao contrário de tentar sintetizar a produção fotográfica recente no país e selecionar os artistas contemporâneos "mais importantes" para essa mostra, o seu curador, Eder Chiodetto, preocupou-se em "fazer um mapeamento das principais linhas de força que surgiram na fotografia brasileira nesta última década". ${ }^{\mathrm{E}}$ o Cia de foto fez parte dessa seleção não apenas com o vídeo "911", mas também com a série intitulada "Guerra" (20082011) produzida através de um particular processo de edição do coletivo a partir de seu próprio arquivo do qual são extraídas não imagens de conflitos bélicos, mas sim de seu "mundo íntimo, imaginado" que "termina por protagonizar um conflito". Afinal, para os seus integrantes "nossa casa, nossos filhos, nossas viagens e paisagens, nosso bairro, as janelas de nossos vizinhos, são lugares e onde essa guerra emana e se pauta não por fatos mas pelo andar fictício de nossas imagens".

Sobre a escolha específica da série "Guerra" e do vídeo "911" do Cia de foto para compor a mostra Geração oo, Chiodetto argumenta que:

O surgimento da Cia de Foto na fotografia brasileira nos anos oo trouxe discussões que ajudaram a refletir sobre tabus até então intocáveis. Os três fotógrafos do coletivo criaram ética e estética próprias, causando polêmicas. Deixar de assinar 
trabalhos individualmente e agregar ao fotojornalismo referências à publicidade e ao cinema, rompendo com a catequese do realismo e expandindo a reportagem para os limites da ficção, foram algumas bandeiras do grupo. Em "Guerra", a Cia seleciona fotos de São Paulo de seu arquivo, e, por meio de edição e tratamento, lhes adiciona uma dramaticidade extra. Assim é possível, pelo viés da ficção, demonstrar o que há de mais real: a sensação de guerra civil que se vive na cidade. No vídeo "911", a Cia faz uma reportagem de rara sensibilidade ao misturar cenas estáticas com movimento. ${ }^{6}$

Os trabalhos desenvolvidos pela Cia de foto parecem adequados para se discutir os conceitos abordados no presente artigo, já que tratam dos limites de representação da fotografia e dos hibridismos presentes nas narrativas documentais atuais, bem como das novas possibilidades de criação e apresentação da realidade social no cenário da comunicação e da arte contemporânea.

As narrativas, sejam elas reais ou imaginárias, buscam descrever num determinado tempo e espaço, as ações e seus personagens. Embora as narrativas ficcionais se diferenciem das factuais por estabelecerem respectivamente relações lógicas e cronológicas com coisas imaginadas e com coisas físicas, ambas são, entretanto, "construções discursivas" que podem tratar diretamente da realidade por meio das mais variadas abordagens e linguagens. E, apesar de as tecnologias digitais terem possibilitado a produção de novas formas de narrativas criativas que tratam da realidade por meio técnicas ficcionais como, por exemplo, a dos moradores registrados no vídeo "911" da Cia de foto, Motta acredita que:

[...] Essa transmutação entre o mundo da estória narrada e o mundo da vida não parece ter se modificado no ambiente virtual das narrativas atuais, mesmo das narrativas voláteis da Internet. As estórias virtuais, ainda que guardem distantes características, seguem envolvendo os receptores e eles prosseguem recriando na imaginação suas próprias significações a partir do que ouvem, leem ou veem nos blogs ou redes sociais embora em moldes diferentes (MOTTA, 2013, p. 73).

Ao contrário da linguagem "direta" e "objetiva" empregada no final do século XIX e início do século XX pelos pionei- 
ros do gênero, o documentário fotográfico contemporâneo é, muitas vezes, produzido por autores que não acreditam em registro sem criação e que assumem abertamente a ficção em suas produções e, sobretudo, a subjetividade do olhar, as relações sociais ou subjetivas do fotógrafo com as coisas ou com as pessoas fotografadas e a subjetividade própria da escrita fotográfica (a maneira, o estilo). Ou seja, esses novos paradigmas vão desafiar nossa percepção sobre "a realidade" e contribuir para a construção de uma nova visualidade sobre as questões sociais no mundo.

\section{NOTAS}

1. "[...] digital life exemplifies the trajectory of photography (and cinema) has taken, culminating in a unifying aesthetic of what many call convergence. In convergence, sometimes technology alters practice, gives it a jolt, such as in the advent of mobile telecommunication and the Internet, which has dramatically affected where, how, and with whom we communicate. At other times it is the practice that subsume the new technology and that, despite the academic protest to the contrary, is what has happened in photography and cinema" (SUTTON, 2009, p. 2).

2. [...] the arrival of digital not only is a life-changing technological intervention but returns us to a natural state affairs in which poetics, represented by painting, is the predominant regime (SUTTON, 2009, p. 3).

3. Texto de apresentação do coletivo em seu site (www.ciadefoto.com), que no entanto, encontra-se atualmente indisponível.

4. Eder Chiodetto, curador da exposição, em entrevista ao blog Paraty em Foco no dia 11 de abril de 2011. Ver: <http://paratyemfoco.com/blog/2011/o4/ geracaooo/>. Acesso em: 10 maio 2014.

5. Ver: <http://www.ciadefoto.com/filter/ensaio/GUERRA>. Acesso em: o1 abr. 2016.

6. Texto de apresentação dos trabalhos "Guerra" e "911" da Cia de foto durante a exposição Geração oo, realizada entre os dias 16 de abril de 12 de junho de 2011, no SESC Belenzinho, em São Paulo.

\section{Referências}

BEAUMONT, Newhall. The History of Photography. 5. ed. New York: MOMA, 1997.

MACHADO, Arlindo. Pré-cinema e pós-cinema. Campinas, Papirus, 1997.

MOTTA, Luiz Gonzaga. Análise Crítica da Narrativa. Brasília: Editora Universidade de Brasília, 2013.

PITOF, Jean-Christophe Grange. Vidocq, 2001. (100 min), 
France, dir. Pitof, RF2K/Studio Canal/ TF1, 2001.

ROUILLÉ, André. A fotografia: entre documento e arte contemporânea. São Paulo: Editora Senac São Paulo, 2009.

SUTTON, Damian. Photography, cinema, memory: the crystal image of time. Minneapolis: Minnesota Press, 2009.

Recebido em: 08/03/16

Aceito em: 07/05/16

\section{RAFAEL CASTANHEIRA}

rafaelcastanheira@hotmail.com

Rafael Castanheira nasceu em Goiânia, GO, 1977. Vive e trabalha em Brasília, DF. Fotógrafo e pesquisador, é doutorando em Comunicação pela Universidade de Brasília (UnB) e mestre em Artes e Cultura Visual pela Universidade Federal de Goiás (UFG). Atuou como fotojornalista e assessor de comunicação no Rio de Janeiro, Brasília, Amazonas e Mato Grosso. Desde 2007 trabalha como professor de fotografia, tendo lecionado na UFG, PUC (GO) e no Instituto de Ensino Superior de Brasília (IESB). Atualmente, desenvolve projetos pessoais em fotografia, como ensaios, pesquisas e curadorias. 